\title{
Tc99m Kullanımının Kütle Spektrometri Tekniğiyle Ölçülen Takrolimus, Everolimus, Sirolimus ve Siklosporin A Düzeylerine Etkisinin Değerlendirilmesi
}

\section{Evaluation of the Effect of Tc99m Usage on Tacrolimus, Everolimus, Sirolimus and Cyclosporin A Levels Measured by Mass Spectrometry}

\author{
Mehmet Zeki YILMAZTEKIN ${ }^{1} \mathbb{D}$, Ataman GÖNEL ${ }^{2}{ }^{\mathbb{D}}$,Ahmet GÜZELÇiçEK ${ }^{3}{ }^{\mathbb{D}}$, İsmail KOYUNCU ${ }^{2} \mathbb{D}$, \\ Nihayet BAYRAKTAR ${ }^{2}$ (D)
}

1Harran Üniversitesi Tıp Fakültesi, Nükleer Tıp Anabilim Dalı, Şanlıurfa, Türkiye

2 Harran Üniversitesi Tıp Fakültesi, Tıbbi Biyokimya Anabilim Dalı, Şanlıurfa, Türkiye

3 Harran Üniversitesi Tıp Fakültesi, Çocuk Sağlığı ve Hastalıkları Anabilim Dalı, Şanlıurfa, Türkiye

öz.

Amaç: Sintigrafik görüntüleme tekniklerinde kullanılan Tc99m maruziyetinin kan LC/MS-MS ile ölçümü yapılan takrolimus, everolimus, sirolimus ve siklosporin A düzeylerine etkisinin deneysel araştırılmasıdır.

Materyal ve Metod: Çalışma için HPLC solvent ve reaktifleri (Jasem, Türkiye) ilekalibratör ve kontrol solüsyonları kullanıldı. İterferans çalışması için Tc99m preparatı kullanıldı. İmmunsupresan ölçümü ShimadzuNexera X2 ultra yüksek performans likit kromatografi (UHPLC) ile entegrasyonu sağlanmış Shimadzu 8045 triplequadrupole kütle spektrometrisi (MS/MS) (Shimadzu, Japan) ile yapıldı. Cihaz verileri Shimadzu Software ile hesaplandı. Örnek hazırlama için, 500 mikrolitre(uL) kontrol solusyonu santrifüj tüpüne alındı. Üzerine 25 uLinternalstandard eklenip 5 saniye vorteksle karıştıııldı. İnterferans çalışması için tüm işlemler level1, level2 ve level3 kontrol solüyonları için tekrarlandı ve cihaza okutuldu. Her seviye kontrole 50 uLdistile su eklenerek interferans çalışması tekrarlandı.

Bulgular: Sirolimus ölçümlerinde \%6,28 - \%47,21 aralı̆ı̆ında bias tespit edildi. Takrolimus düzeyleri \%21,81 ile \%44,62 aralığında hedef değerden saptı. Siklosporin A seviyeleri için \%9,30- \%43,16 oranları arasında bias hesaplandı. En az sapma \%6,28 ile Sirolimus seviye 3 de, en fazla sapma sirolimus seviye 1 de gözlendi.

Sonuç: Sintagrafik çekimlerde kullanılan Tc99m radyonüklidinin LC/MS-MS cihazlarıyla ölçümü yapılan immunsüpresan düzeylerini etkileyebilme potansiyeli bulunmaktadır. Bu konuda numune alımı yapan sağık personelleri bilgilendirilmeli, şüpheli sonuçlarda hekimler interferans ihtimalini düşünmelidir.

Anahtar kelimeler: Tc99m, İnterferans, LC/MS-MS

Abstract

Background: To investigate the effect of Tc99m exposure on tacrolimus, everolimus, sirolimus and cyclosporin A levels measured by blood LC / MSMS used in scintigraphic imaging techniques.

Materials and Methods: HPLC solvents, reagents (I Jasem, Turkey), calibrator and control solutions for the study were employed. The Tc99m preparation was used for the interference study. Immunosuppressant measurement was performed by Shimadzu 8045 triple quadrupole mass spectrometry (MS / MS) (Shimadzu, Japan), which was integrated with Shimadzu Nexera X2 ultra high-performance liquid chromatography (UHPLC). Device data was calculated with Shimadzu Software. For sample preparation, 500 microliters (LL) of control solution was transferred to the centrifuge tube. $25 \mathrm{uL}$ of internal standard was added and mixed with vortex for 5 seconds. All procedures for interference study were repeated for level1, level 2 and level 3 control solutions and performed by LC/MS-MS. Interference protocol was repeated by adding $50 \mathrm{uL}$ of distilled water to each level of control.

Results: Bias was detected in the range of $6.28 \%$ to $47.21 \%$ in all sirolimus measurements. Tacrolimus levels deviated from the target value in the range of $21.81 \%$ to $44.62 \%$. For cyclosporine A levels, bias was calculated between $9,30 \%-43,16 \%$. The least deviation was observed in Sirolimus level 3 with $6.28 \%$ and the maximum deviation was observed in sirolimus level 1.

Conclusion: The Tc99m radionuclide used in scintigraphic imaging has the potential to affect immunosuppressant levels measured by LC / MS-MS devices. Health service staffs making sampling should be informed about this and physicians should consider the interference posibility in suspicious immunosuppressant concentrations.

Key words: Tc99m, Interference, LC/MS-MS
Sorumlu Yazar 1

Corresponding Author

Dr. Ataman GÖNEL

Harran Üniversitesi, Tıp Fakültesi

Tıbbi Biyokimya Anabilim Dalı, Osmanbey Kampüsü 63300 Haliliye Şanlıurfa

Tel: +90 (0414) 3444444

Fax : +90 (414) 3183209

E-mail: atamangonel@gmail.com

Geliş tarihi / Received:

23.11.2019

Kabul tarihi / Accepted: 04.12.2019

DOI: $10.35440 /$ hutfd.650152 


\section{Giriş}

Böbrek transplantasyonu yapılan hastalarda böbreğin anatomik durumu, ürolojik ve vasküler komplikasyonlar, akut tübüler nekroz (ATN) ve akut reddetme (AR) gibi nakil sonrası komplikasyonları tanımak için klinisyenler birkaç tanısal yöntem kullanabilir $(1,2)$. Halen, nakil sonrası böbrek fonksiyon bozukluğunu değerlendirmek için en iyi yöntemsel yaklaşım konusunda fikir birliği yoktur. Genellikle AR tanısı için altın standart olarak kabul edilen renal iğne biyopsisi sıklıkla gereklidir. Ancak, bu invazivdir ve örnek hatalara veya komplikasyonlara neden olabilir. Çoğu klinisyen ultrasonografi, bilgisayarlı tomografi (BT), manyetik rezonans görüntüleme (MRG) ve renal sintigrafi gibi invaziv olmayan yöntemlerden birini kullanmayı tercih ederm(3-5). Sintigrafik görüntüleme yapılan immünsüpresyona maruz hastaların, kan immunsupresan düzeylerinin takibi rejeksiyon riskini en aza indirmek açısından önemlidir. Organ fonksiyon devamlılığı için görüntüleme yapilırken immunsupresyonun da optimum düzeyde tutulması gerekir (6-8). Rutin olarak kullanılan immunoassay tekniklerin yanında kullanılan immunsupresanın doğru ölçümü için LC/MS-MS tekniğinin kullanımı tercih edilmektedir (9-11). Numune örneklem zamanının uygun olmayan bir zamanda yapılması testler için referans kabul edilen immunsupresan düzeylerini etkileyebilir. Bu çalışmanın amacı Tc99m kullanımında kan LC/MS-MS ile ölçümü yapılan takrolimus, everolimus, sirolimus ve siklosporin A düzeylerinin interferansa maruziyetinin deneysel araştırılmasıdır.

\section{Materyal ve Metot}

Çalışma öncesi altı seviyeli kalibrasyon ve sonrasında üç seviye kontrol ile yöntem çalışabilirliği konfirme edildi. JASEM firması tarafından üretilmiş HPLC solvent ve reaktifleri ile kalibratör ve kontrol solüsyonları kullanıldı. İnterferans çalışması için Tc99m preparatı kullanıldı. Immunsuprsan ölçümü Shimadzu Nexera X2 ultra yüksek performans likit kromatografi (UHPLC) ile entegrasyonu sağlanmış Shimadzu 8045 triple quadrupole kütle spektrometrisi (MS/MS) (Shimadzu, Japan) ile yapıldı. Cihaz verileri Shimadzu Software ile hesaplandı. Örnek hazırlama için, 500 mikrolitre(uL) kontrol solusyonu santrifüj tüpüne alındı. Üzerine $25 \mathrm{uL}$ internal standard eklenip 5 saniye vorteksle karıştııldı. Sonra üzerine 975 uL çöktürücü özelliğindeki reaktif-1 eklenip 15 saniye vorteksle tekrar karıştıııldı. Elde edilen karışım 3000 rpm de 5 dakika santrifüj edildi. Süpernatant viale alınıp Shimadzu 8045 LC-MS / MS cihazında okutuldu. Benzer işlemler level1, level2 ve level3 kontrol solüyonları için tekrarlandı ve cihaza okutuldu. İnterferans çalışması için her seviye kontrole 50 uL distile su eklenerek ön aşama ve okutma işlemleri tekrarlandı. Tc99m preparatından $50 \mathrm{uL}$ alınarak her seviye kontrole ekleme yapıldı ve ölçümler tekrarlandı. Her seviye kontrol solüsyonu, kontrol + 50uL distile su
(V1), ve kontrol + 50uL Tc99m (V2) karışımları ayrı ayrı 3 tekrar yapılarak çalışıldı ve ortalama değerleri alınarak bias=(V2-V1)/V1 formülüne göre sapma yüzdeleri hesaplandı. Her kontrol seviyesine volüm genişlemesine bağlı oluşacak interferansı ekarte etmek için $50 \mathrm{uL}$ distile su eklenerek elde edilen sonuçlar hedef değer (V1) olarak kabul edildi. Bu deneysel çalışma insan veya hayvan numunesi içermediğinden etik kurul onayı gerektirmemektedir.

bias $=(\mathrm{V} 2-\mathrm{V} 1) / \mathrm{V} 1$

\section{Bulgular}

Everolimus ölçümlerinden elde edilen sonuçlarda hedef değerden \% 18,65 - \% 38,93 aralığında sapma gözlendi. Sirolimus ölçümlerinde \% 6,28 - \% 47,21 aralığında bias tespit edildi. Takrolimus düzeyleri $\% 21,81$ ile $\% 44,62$ aralığında hedef değerden saptı. Siklosporin A seviyeleri için $\% 9,30$ - \%43,16 oranları arasında bias hesaplandı. Seviye 2 kontrol solüsyonundaki sapma aralığı $\% 16,14$ ile \%31,31 arasında hesaplandı. Seviye3 kontrol solüsyonuna ekleme yapılarak elde edilen sonuçlarda hedef değerden sapma miktarları \% 20,56 - \% 39,62 aralığında idi. Düşük konsantrasyon immunsupresan düzeyleri yüksek konsantrasyon immunsupresanlara göre daha fazla oranda hedef değerden sapma eğilimi gösterdi. Seviye 3 konsantrasyonda \% 6,28- \% 21,81 arasında sapma meydana gelirken, seviye 1 konsantrasyonda \%38,93-\%47,21 oranları arasında daha yüksek bias değerleri elde edildi. En az sapma \%6,28 ile Sirolimus seviye 3 'de, en fazla sapma sirolimus seviye 1'de gözlendi.

Tablo 1. İmmunsupresan seviyelerinin Tc99m uygulaması ile hedef değerden sapma yüzdeleri (bias).

\begin{tabular}{|c|c|c|c|c|c|}
\hline İLAÇ & & $\begin{array}{c}\text { Kontrol } \\
\text { Materyali } \\
+ \\
\text { distile su } \\
\text { (V1) (ng/dL) }\end{array}$ & $\begin{array}{c}\text { Kontrol } \\
\text { Materyali } \\
+ \\
\text { Tc99m } \\
\text { (V2) (ng/dL) }\end{array}$ & $\begin{array}{c}\text { BiAS } \\
\text { (ng/dL) }\end{array}$ & $\begin{array}{c}\text { BIAS } \\
(\%)\end{array}$ \\
\hline \multirow{3}{*}{ EVEROLIMUS } & Seviye1 & 2,44 & 3,22 & 0,95 & 38,93 \\
\hline & Seviye2 & 6,10 & 8,01 & 1,91 & 31,31 \\
\hline & Seviye3 & 9,81 & 11,64 & 1,83 & 18,65 \\
\hline \multirow{3}{*}{ SIROLIMUS } & Seviye1 & 3,05 & 4,49 & 1,44 & 47,21 \\
\hline & Seviye2 & 11,38 & 13,73 & 2,35 & 20,65 \\
\hline & Seviye3 & 19,74 & 20,98 & 1,24 & 6,28 \\
\hline \multirow{3}{*}{ TAKROLIMUS } & Seviye1 & 2,51 & 3,63 & 1,12 & 44,62 \\
\hline & Seviye2 & 4,87 & 6,04 & 1,17 & 24,02 \\
\hline & Seviye3 & 9,26 & 11,28 & 2,02 & 21,81 \\
\hline \multirow{3}{*}{$\begin{array}{l}\text { SIKLOSPORIN } \\
\text { A }\end{array}$} & Seviye1 & 41,98 & 60,11 & 18,13 & 43,19 \\
\hline & Seviye2 & 84,61 & 98,27 & 13,66 & 16,14 \\
\hline & Seviye3 & 166,41 & 181,89 & 15,48 & 9,30 \\
\hline
\end{tabular}




\section{Tartışma}

Böbrek transplantasyonu sonrası hastaların bakımı ve klinik takibi rejeksiyon riskini azaltmak için önemlidir (12, 13). Bunun için yapılan görüntüleme yöntemlerinden bir tanesi Tc99m ile yapılan sintigrafi çekimleridir. Bu çekimler sırasında hastalara uygulanan parenteral bir çok ilaç için geçerli olan alerjik yan etkiler Tc99m için de geçerlidir ve klinisyenler tarafından da bilinen istenmeyen bir durumdur $(14,15)$. Gözlemlenebilir bu tür yan etkilerin yanında farkında olunmayan ve tespiti zor olan diyagnostik testlerin de etkilenme durumu söz konusu olabilir. Bunlardan bir tanesi de kanda bulunan bir ksenobiyotiğin ölçümü yapılacak başka parametrelerin analizini etkilemesidir $(16,17)$. Kanda bulunan interferanların oluşturduğu serum matriks kompozisyonunun değişkenliğine bağlı analitik hatalara interferans denir $(9,18,19)$. Hastaların tanısı, klinik takibi için önemli olan ve farkında olunmayan bu durum diyagnostik testlerde gerçekleşebileceği gibi terapötik bir ilaç düzeyi ölçümünde de gerçekleşebilir (9). Terapötik ilaçlardan immunsupresanlar özellikle nakil hastalarının ömür boyu kullanması gereken hayati ilaçlardır (20). Bu ilaçların düzeyini etkileyecek herhangi bir durum optimum düzeyde immunsupresyonu engelleyeceğinden rejeksiyon riski ortaya çıkarabilir. Hastaya uygulanan Tc99m'in yarılanma ömrü geçmeden alınacak bir numuneden yapılan analiz immunsupresan düzeylerini etkileyerek yeterli immunsupresyon oluşumunu engelleyebilir. Analitik fazdaki testlerin etkilenmesi genel olarak interferans olarak adlandırılsa da LC/MS-MS tekniği kullanılarak yapılan ölçümlerdeki girişime matriks etkisi de denmektedir (21).

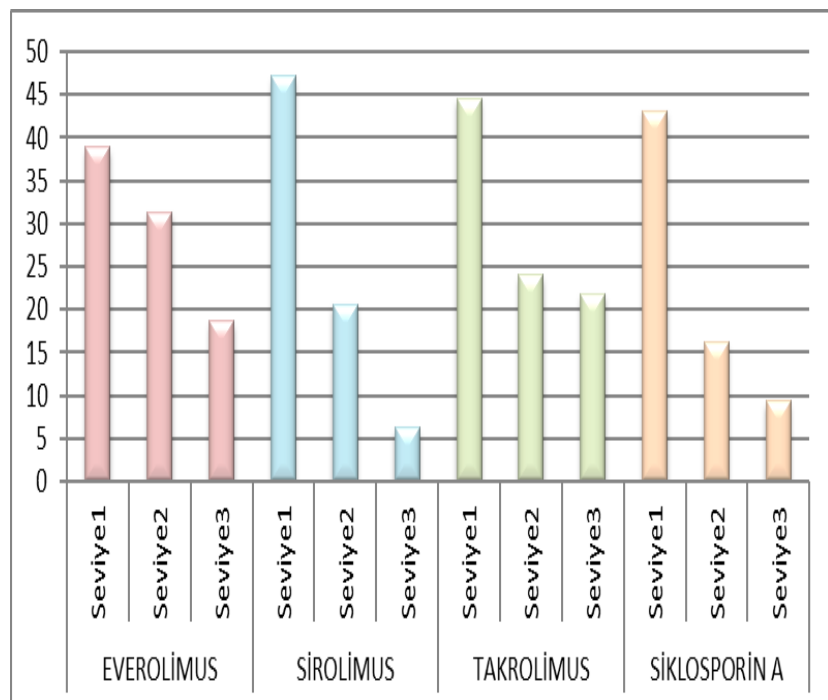

Şekil1. Her seviye için \%bias değerlerinin karşılaştıılması

Invitro olarak yapılan çalışmamızda transplantasyon hastaları için ömür boyu kullanılması gereken ve doz ayarlaması optimize edilmediğinde rejeksiyon riskinin oluşacağı immunsupresanların konsantrasyonları Tc99m'den etkile- nerek, hedef değerden sapmalar göstermiştir. Everolimus ölçümlerinden elde edilen sonuçlarda \% 18,65 - \% 38,93 aralığında, sirolimus ölçümlerinde \% 6,28 - \% 47,21 aralığında, takrolimus düzeylerinde $\% 21,81-\% 44,62$ aralığın$\mathrm{da}$, siklosporin A seviyelerinde $\% 9,30$ - $\% 43,16$ oranları arasında hedef değerden sapma gözlenmiştir. En az sapma \%6,28 ile sirolimus seviye 3 de, en fazla sapma sirolimus seviye 1 'de tespit edilmiştir. Yüksek konsantrasyonlarda düşük oranda, düşük konsantrasyonlarda yüksek oranda sapmanın meydana gelmesi, düşük rakamlardaki küçük oynamaların oransal olarak yüksek sapmalara neden olması ile açıklanabilir. Aynı zamanda LC/MS-MS cihazlarında analizin doğruluğunun ana iyon ve product iyonların doğru oranlarda tespiti ile mümkün olabilmektedir $(22,23)$. Burada Tc99m konsantrasyonun düşük konsantrasyondaki immunsupresanlara müdahalenin göreceli yüksekliğe bağı olarak yüksek konsantrasyonlardaki immunsupresanlara olan müdahaleden oransal olarak daha fazla olacağı söylenebilir. Bu tür radyoaktif ışıma yapan maddelerin analiz sırasında internal standart olarak kullanılan döteryumlu maddeleri etkileme, hatta analitleri döteryumlu hale getirme potansiyeli bulunmaktadır. LC/MS-MS cihazları analiti tespit etmede her ne kadar referans metod gibi görünse de bu tür interferanlara hassas olduklarını unutmamak gereklidir (24-26). Burada ölçümü yapılan immunsupresanların hepsi birbirine yakın oranlarda etkilenmiş olması interferansın kaçınılması için nakil hastalarında tercih edilecek immunsupresan türü için birini diğerine karşı üstünlüğünü olmadığını göstermektedir. Yani bütün immunsüpresanların kullanımında bu tür bir durum için dikkatli olunmalıdır. Daha önce yapılan immunsupresanların görüntüleme yöntemlerinde kullanılan radyoopak maddelerden de etkilendiği benzer invitro inteferans çalışması ile de ispatlanmıştır. Bu tür bir analitik hata durumu her terapotik ve diyagnostik ilaç için geçerli olabilir $(9,16)$. Hangi ksenobiyotiğin hangi testi ne zaman etkileyeceğine dair kesin bilgi ve herhangi bir veri bankası bulunmamaktadır. Klinik takipte unutulmamalıdır $\mathrm{ki}$, diyagnostik testlerdeki hatalı yüksek sonuçlar hatalı tanı ve gereksiz hospitalizasyona, immunsupresanlardaki hatalı yüksek sonuçlar hatalı doz kısıtlamasına bağı yeterli immunsupresyon oluşmamasına neden olabilir. Yeterli düzeyde yapılmayan immunsupresyon nakil hastalarında rejeksiyon riskini arttırabilir.

Bu çalışmanın kısıtılığı inteferans çalışmalarının insan fizyolojisi ve metabolik durumunun inteferan üzerindeki etkisine yapacağı müdahalenin tespiti zorluğundan dolayı invitro ortamda yapılma zorunluluğudur. Aynı zamanda doz ayarlamasının hayati öneme sahip olduğu ve sürekli rejeksiyon riski taşıyan nakil hastalarının bu tür bir çalışmaya dahil edilmesi etik inlaller oluşturabilir. Ek olarak, ilaçların vücuttan atılma zamanları, kullanılan kit ve ölçüm yöntemlerinin hedef değerden sapma oranlarını etkileyebilmesi yine diğer bir kısıtlııktır. 
Hastane ortamlarında nakil hastaları için önemli olan numune alım zamanlarının dikkat edilmesi, özellikle sintigrafik çekimlerde kullanılan $\mathrm{Tc} 99 \mathrm{~m}$ radyonüklidinin LC/MS-MS cihazlarıyla ölçümü yapılan immunsüpresan düzeylerini etkileyebileceğinin bilinmesi, bu konuda numune alımı yapan sağık personellerinin bilgilendirilmesi, şüpheli sonuçlarda hekimlerin inteferans intimalini de düşünmesi nakil hastalarının immunsupresyon durumlarının optimizasyonu açısından faydalı olabilir.

\section{Kaynaklar}

1. Rao KV, Kjellstrand CM. Post transplant acute renal failure: a review. Clinical and experimental dialysis and apheresis. 1983;7(12):127-43.

2. Jehn U, Schuette-Nuetgen K, Kentrup D, Hoerr V, Reuter S. Renal Allograft Rejection: Noninvasive Ultrasound- and MRI-Based Diagnostics. Contrast Media Mol Imaging. 2019;2019:3568067.

3. Benjamens S, Berger S, Glaudemans A, Sanders J, Pol R, Slart R. Renal scintigraphy for post-transplant monitoring after kidney transplantation. Transplantation Reviews. 2018;32(2):102-9.

4. Krill AJ, Palestro CJ. Principles of Nuclear Medicine Imaging. Pediatric and Adolescent Urologic Imaging: Springer; 2014. p. 89-112.

5. Elgazzar $\mathrm{AH}$, Wagner J. A concise guide to nuclear medicine: Springer; 2011.

6. Transplant BC. Clinical guidelines for kidney transplantation. 2015.

7. Halloran PF. Immunosuppressive drugs for kidney transplantation. New England Journal of Medicine. 2004;351(26):2715-29.

8. Shapiro R, Basu A, Tan H, Gray E, Kahn A, Randhawa P, et al. Kidney transplantation under minimal immunosuppression after pretransplant lymphoid depletion with Thymoglobulin or Campath. Journal of the American College of Surgeons. 2005;200(4):505-15.

9. Gönel A, Koyuncu I. False Immunosuppressant Measurement by LC-MS/MS Method Due to Radiopaque Agents. Combinatorial chemistry \& high throughput screening. 2019;22(2):129-34.

10. Karapirli M, Kizilgun M, Yesilyurt O, Gul H, Kunak ZI, Akgul EO, et al. Simultaneous determination of cyclosporine A, tacrolimus, sirolimus, and everolimus in whole-blood samples by LC-MS/MS. The Scientific World Journal. 2012;2012.

11. Pohanka A, Rosenborg S, Lindh JD, Beck O. Experiences from using LC-MS/MS for analysis of immunosuppressive drugs in a TDM service. Clinical biochemistry. 2016;49(13-14):1024-31.

12. Baker RJ, Mark PB, Patel RK, Stevens KK, Palmer N. Renal association clinical practice guideline in post-operative care in the kidney transplant recipient. BMC nephrology. 2017;18(1):174.

13. Gatault $P$, Kamar N, Büchler M, Colosio $C$, Bertrand D, Durrbach $A$, et al. Reduction of extended-release tacrolimus dose in low-immunological-risk kidney transplant recipients increases risk of rejection and appearance of donor-specific antibodies: a randomized study. American Journal of Transplantation. 2017;17(5):1370-9.

14. Makaryus JN, Makaryus AN, Azer V, Diamond JA. Angioedema after injection of Tc-99m sestamibi tracer during adenosine nuclear stress testing. Journal of Nuclear Cardiology. 2008;15(4).

15. Silindir M, Ozer A. Adverse reactions to radiopharmaceuticals (ARRP): particularly to technetium radiopharmaceuticals. FABAD J Pharm Sci. 2008;33:109-17.

16. Tascanov MB, Gönel A. How Do Contrast Agents Affect Cardiac Markers and Coagulation Tests? Experimental Study. Comb Chem High Throughput Screen. 2019;22(5):355-60.

17. Gönel A. 25-OH Vitamin D Düzeyi Ölçümünde Radyoopak Madde İnterferansının Deneysel Araştırıması. Harran Üniversitesi Tıp Fakültesi Dergisi.15(3):182-5.

18. Gönel A. Akrep Antivenomunun İmmunassay Yöntem Üzerindeki İnterferans Etkisinin Deneysel Araştırıması. Harran Üniversitesi Veteriner Fakültesi Dergisi.7(2):179-85.
19. Gonel A, Yetisgin A. False Negative D Vitamin Measurement in LC-MS/MS Method Due to Hyperlipidemia: Case Report. Combinatorial Chemistry \& High Throughput Screening. 2019;22(6):428-30.

20. Field MJ, Lawrence RL, Zwanziger L. Transplantation and Immunosuppressive Medications: Evolution of Medicare Policy Involving Transplantation and Immunosuppressive Medications-Past Developments and Future Directions. Extending Medicare Coverage for Preventive and Other Services: National Academies Press (US); 2000. 21. Van Eeckhaut A, Lanckmans K, Sarre S, Smolders I, Michotte Y. Validation of bioanalytical LC-MS/MS assays: evaluation of matrix effects. Journal of Chromatography B. 2009;877(23):2198-207.

22. Geromanos SJ, Vissers JP, Silva JC, Dorschel CA, Li GZ, Gorenstein MV, et al. The detection, correlation, and comparison of peptide precursor and product ions from data independent LC-MS with data dependant LC-MS/MS. Proteomics. 2009;9(6):1683-95.

23. Pitt JJ. Principles and applications of liquid chromatography-mass spectrometry in clinical biochemistry. The Clinical Biochemist Reviews. 2009;30(1):19.

24. Wu AH. Tietz clinical guide to laboratory tests-E-book: Elsevier Health Sciences; 2006.

25. Grebe SK, Singh RJ. LC-MS/MS in the clinical laboratory-where to from here? The Clinical Biochemist Reviews. 2011;32(1):5.

26. Shi RZ, van Rossum HH, Bowen RA. Serum testosterone quantitation by liquid chromatography-tandem mass spectrometry: Interference from blood collection tubes. Clinical biochemistry. 2012;45(18):1706-9. 